\title{
NANO ALMOST I-OPENNESS AND NANO ALMOST I-CONTINUITY
}

\author{
A. A. Nasef* and A. A. Azzam** \\ *Department of Physics and Engineering Mathematics, Faculty of Engineering, Kafr El-Sheikh University, Kafr El-Sheikh, Egypt. \\ nasefa50@yahoo.com \\ **Department of Mathematics, Faculty of Science, Assuit University, New Valley Branch, Egypt. azzam0911@yahoo.com.
}

Received 31/5/2017 Revised 10/7/2017 Accepted 20/7/2017

\begin{abstract}
Our purpose is to present the nano almost $I$-open and nano almost $I$-closed sets. Utilizing these new concepts the nano almost $I$-continuous functions have been obtained. We give a diagram that well illustrates the relations.
\end{abstract}

AMS Mathematics Subject Classification: (2010) 54A05, 54A10 and 54B05.

Keywords: Nano ideal, nano local function, topological ideal, nano topological ideal.

\section{Introduction}

Topological spaces with ideals have been considered since 1930 by Kuratowski [1]. The paper of Vaidyanathaswamy [2] in 1945 gave the subject great importance.

"A non-empty collection of subsets of $X$ with heredity and finite additivity conditions is called as an ideal or a dual filter on $X$. Namely a non-empty family $I \subseteq P(X)(P(X)$ is the set of all subsets of $X)$ is nammed an ideal if and only if:

i) $A \in I$ gives $P(A) \subseteq I$ (heredity).

ii) $A, B \in I$ gives $A \cup B \in I$ (finite additivity).

Given $X$ carries topology $\tau$ with an ideal $I$ on $X$, a set operator( $)^{*}: P(X) \rightarrow P(X)$, named a local function [2] of $A$ with respect to $\tau$ and $I$ is defined as follows: for $A \subseteq X, A^{*}(I, \tau)=\left\{x \in X: G_{x} \cap A \notin I\right.$ for every $\left.G_{x} \in \tau(x)\right\}$ where $\tau(x)=\{G \in \tau: x \in G\}$. A Kuratowski closure operator $C l^{*}()$ for a topology $\tau^{*}(I, \tau)$, named the $*$-topology finer than $\tau$ is defined by $C l^{*}(A)=A \cup A^{*}(I, \tau)[2]$. When there is no chance for confusion, we will simply write $A^{*}$ for $A^{*}(I, \tau)$ and $\tau^{*}$ for $\tau^{*}(I, \tau)$. If $I$ is an ideal on $X$, then the space $(X, \tau, I)$ is called an ideal topological space".

"The concept of nano topology was introduced by Lellis Thivagar and Carmel Richard [3] which was defined in terms of approximations and boundary region of a subset of an universe using an equivalence relation on it and also they defined nano closed sets, nono interior and nano-closure".

The concept of nano ideal topological spaces was introduced by Parimala et al. [4] and studied its properties and characterizations.

The basic object of this paper is to present the nano almost $I$-open and nano almost $I$-closed sets. Utilizing these new concepts the nano almost $I$-continuous functions have been obtained. Nano almost $I$-openness and nano almost $I$-continuity are considered as a generalization of nano $I$-openness and nano $I$-continuity which are known before. Numerous nano topological properties of these new notions have been discussed. 


\section{Preliminaries}

Before entering our working, we have compiled some basic facts on rough sets.

Definition 2.1. "(see[5]) Let $U$ be a non-empty finite set of objects named the cosmos and $R$ be an equivalence relation on $U$ named as indiscernibility relation. Then $U$ is divided into disjoint equivalence classes. Elements belonging to the some equivalence class are said to be indiscernible with one another. The pair $(U, R)$ is said to be the approximation space. The lower approximation of $X$ with respect to $R$ is denoted by $\operatorname{apr}(X)$. That is, $\operatorname{apr}(X)=\cup\{R(x): R(x) \subseteq X ; x \in U\}$, The upper approximation of $X$ with respect to $R$ is denoted by $\overline{\overline{a p r}}(X)$. That is, $\overline{\operatorname{apr}}(X)=\cup\{R(x): R(x) \cap X \neq \phi ; x \in U\}$ and the boundary region of $X$ with respect to $R$ is denoted by $B_{R}(X)$. That is, $B_{R}(X)=\overline{\operatorname{apr}}(X)-\underline{\operatorname{apr}}(X)$ as Figure 1".

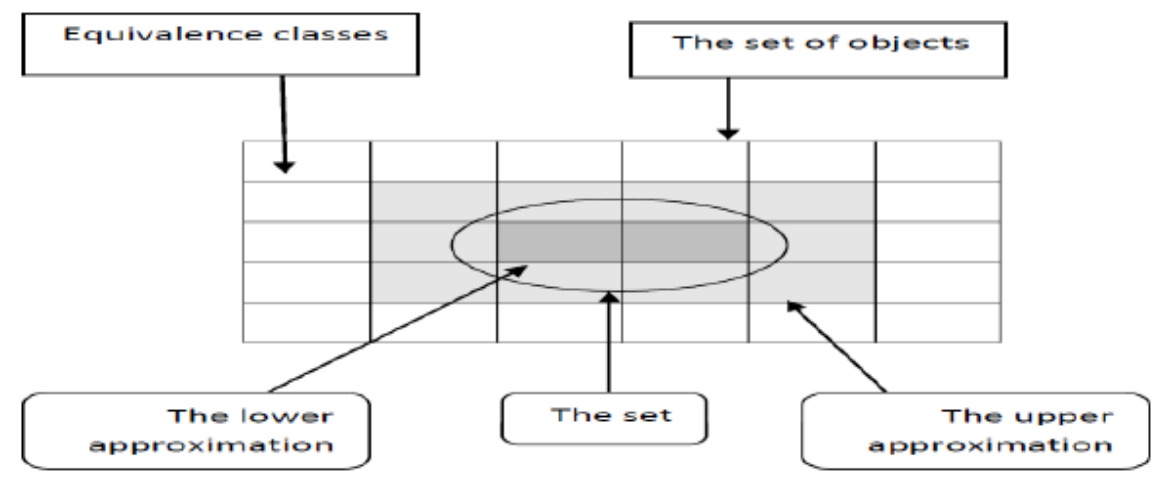

Figure 1: Rough set.

Proposition 2.2." ([5], Proposition 2.2) If $(U, R)$ is an approximation space and $X, Y \subseteq U$, then:

(i) $\underline{\operatorname{apr}}(X) \subseteq X \subseteq \overline{\operatorname{apr}}(X)$.

(ii) $\underline{\operatorname{apr}}(\phi)=\overline{\operatorname{apr}}(\phi)=\phi$.

(iii) $\underline{\operatorname{apr}}(U)=\overline{\operatorname{apr}}(U)=U$.

(iv) $\overline{\operatorname{apr}}(X \cup Y)=\overline{a p r}(X) \cup \overline{a p r}(Y)$.

$(v) \overline{a p r}(X \cap Y) \subseteq \overline{a p r}(X) \cap \overline{a p r}(Y)$.

(vi) $\underline{\operatorname{apr}}(X \cup Y) \supseteq \underline{\operatorname{apr}}(X) \cup \underline{\operatorname{apr}}(Y)$.

(vii) $\underline{\operatorname{apr}}(X \cap Y)=\underline{\operatorname{apr}}(X) \cap \underline{\operatorname{apr}}(Y)$.

(viii) $\underline{\operatorname{apr}}(X) \subseteq \overline{\operatorname{apr}}(Y)$ and $\overline{\operatorname{apr}}(X) \subseteq \overline{\operatorname{apr}}(Y)$, whenever $X \subseteq Y$.

(ix) $\overline{\operatorname{apr}}\left(X^{c}\right)=[\underline{\operatorname{apr}}(X)]^{c}$ and $\underline{\operatorname{apr}}\left(X^{c}\right)=[\overline{\operatorname{apr}}(X)]^{c}$.

(x) $\overline{\operatorname{apr}}[\overline{\operatorname{apr}}(X)]]=[\underline{\operatorname{apr}}[\overline{\operatorname{apr}}(X)]]=\overline{\operatorname{apr}}(X)$.

(xi) $\underline{\operatorname{apr}}[\underline{\operatorname{apr}}(X)]=\overline{\operatorname{apr}}[\underline{\operatorname{apr}}(X)]=\underline{\operatorname{apr}}(X) ”$.

Definition 2.3. "(see[3]) Let $U$ be the cosmos, $R$ be an equivalence relation on $U$ and $\tau_{R}(X)=\left\{U, \phi, \underline{a p r}(X), \overline{a p r}(X), B_{R}(X)\right\}$, where $X \subseteq U$. Then by Proposition 2.2, $\tau_{R}(X)$ satisfies the condition of topology on $U$.

That is, $\tau_{R}(X)$ is a topology on $U$ called the nano topology on $U$ with respect to $X$ and the pair $\left(U, \tau_{R}(X)\right)$ is called a nono 
topological space. The elements of $\tau_{R}(X)$ are called nano open sets in $U$ and the complement of a nano open set is called a nano closed set. Elements of $\left[\tau_{R}(X)\right]^{c}$ being called duel nano topology of $\tau_{R}(X)$ ".

Remark 2.4. "Let $\left(U, \tau_{R}(X)\right)$ be a nano topological space with respect to $X$ where $X \subseteq U$ and $R$ be an equivalence relation on $U$. Then $U / R$ denotes the family of equivalence classes of $U$ by $R$ ".

Definition 2.5. "Let ([3], Definition 3.1) $\left(U, \tau_{R}(X)\right)$ be a nano topological space and $A \subseteq U$. Then $A$ is said to be:

(i) nano semi-open if $A \subseteq n C l(n \operatorname{Int}(A))$,

(ii) nano preopen if $A \subseteq n \operatorname{Int}(n C l(A))$,

(iii) nano $\beta$-open if $A \subseteq n C l(n \operatorname{Int}(n C l(A)))$ ".

Definition 2.6. "Let $\left(U, \tau_{R}(X)\right)$ and $\left(V, \tau_{R^{\prime}}(Y)\right)$ be two nano topological spaces. A mapping $f:\left(U, \tau_{R}(X)\right) \rightarrow\left(V, \tau_{R^{\prime}}(Y)\right)$ is called

(i) nano continuous [6] if $f^{-1}(B)$ is nano open in $U$ for every nano open set $B$ in $V$.

(ii) nano semi-continuous [6] if $f^{-1}(B)$ is nano semi-open in $U$ for every nano open set $B$ in $V$.

(iii) nano precontinuous [6] if $f^{-1}(B)$ is nano preopen in $U$ for every nano open set $B$ in $V$.

(iv) nano $\beta$-continuous [7] if $f^{-1}(B)$ is nano $\beta$-open in $U$ for every nano open set $B$ in $V$ ".

\section{$3 \quad$ Nano Ideal Topological Spaces}

Recently in 2016, Thivagar and Devi [8] have considered the nano local function in nano ideal topological space and they have obtained a new topology. Before starting the discussion we shall consider the following concepts.

Definition 3.1. "([8], Definition 3.2) Let $\left(U, \tau_{R}(X), I\right)$ be a nano ideal topological space. A set operator ()$_{n}^{*}: P(U) \rightarrow P(U)$ is named the nano local function. And for a subset $A \subseteq U . A_{n}^{*}\left(I, \tau_{R}(X)\right)=\left\{x \in U: G_{x} \cap A \notin I\right.$, for every $\left.G_{x} \in \tau_{R}(X)\right\}$ is named the nano local function of $A$ with respect to $I$ and $\tau_{R}(X)$. We will simply write $A_{n}^{*}$ for $A_{n}^{*}\left(I, \tau_{R}(X)\right)$ ".

Example 3.2. "Let $\left(U, \tau_{R}(X)\right)$ be a nano topological space with an ideal $I$ on $U$ and for every $A \subseteq U$.

(i) If $I=\{\phi\}$, then $A_{n}^{*}=n C l(A)$,

(ii) If $I=P(U)$, then $A_{n}^{*}=\phi ”$.

Theorem 3.3. "([8], Theorem 3.3) Let $\left(U, \tau_{R}(X)\right)$ be a nano topological space with ideals $I, J$ on $U$ and $A, B$ be subsets of $U$. Then the following statements are true:

(i) $A \subseteq B \Rightarrow A_{n}^{*} \subseteq B_{n}^{*}$,

(ii) $I \subseteq J \Rightarrow A_{n}^{*}(J) \subseteq A_{n}^{*}(I)$,

(iii) $A_{n}^{*}=n C l\left(A_{n}^{*}\right) \subseteq n C l(A)$ ( $A_{n}^{*}$ is a nano closed subset of $\left.n C l(A)\right)$,

(iv) $\left(A_{n}^{*}\right)_{n}^{*} \subseteq A_{n}^{*}$,

(v) $A_{n}^{*} \cup B_{n}^{*}=(A \cup B)_{n}^{*}$,

(vi) $A_{n}^{*}-B_{n}^{*}=(A-B)_{n}^{*}-B_{n}^{*} \subseteq(A-B)_{n}^{*}$,

(vii) $V \in \tau_{R}(X) \Rightarrow V \cap A_{n}^{*}=V \cap(V \cap A)_{n}^{*} \subseteq(V \cap A)_{n}^{*}$ and

(viii) $E \in I \Rightarrow(A \cup E)_{n}^{*}=A_{n}^{*}=(A-E)_{n}^{*}$.

The converse implications of (i), (ii) and (iii) of Theorem 3.3 do not hold in general, as seen from the next instance

Example 3.4. Let $U=\{1,2,3,4\}$ be the universe.

(i) If $X=\{1,2\} \subseteq U ; U / R=\{\{1\},\{3\},\{2,4\}\}$. One can deduce that $\operatorname{apr}(X)=\{1\}, \overline{\operatorname{apr}}(X)=\{1,2,4\}, B_{R}(X)=\{2,4\}$, then $\tau_{R}(X)=\{U, \phi,\{1\},\{2,4\},\{1,2,4\}\}$. Let $I=\{\phi,\{1\}\}$ for $A=\{1,3\}$ and $B=\{1,4\}$, we have $A_{n}^{*}=\{3\}, B_{n}^{*}=\{2,3,4\}$, that is $A_{n}^{*} \subseteq B_{n}^{*}$ but $A$ not subset from $B$. Also, let $I=\{\phi,\{1\}\}$ and $J=\{\phi,\{2\}\}$. It is easily seen that, for $A=\{1,3,4\}$, $A_{n}^{*}(I)=\{2,3,4\}, A_{n}^{*}(J)=\{1,2,3,4\}=U$, that is $A_{n}^{*}(I) \subseteq A_{n}^{*}(J)$, while I not a subset from $J$.

(ii) Let $X=\{1,4\}, U / R=\{\{2\},\{4\},\{1,3\}\}$. One can deduce that $\operatorname{apr}(X)=\{4\}, \overline{\operatorname{apr}}(X)=\{1,3,4\}, B_{R}(X)=\{1,3\}$, then $\tau_{R}(X)=\{U, \phi,\{4\},\{1,3\},\{1,3,4\}\}$. Let $I=\{\phi,\{4\}\}$ for $A \bar{\equiv}\{2,4\}$, we have $n C l(A)=n C l(\{2,4\})=\{2,4\}$, $A_{n}^{*}=\{2,4\}_{n}^{*}=\{2\}$ and $n C l\left(A_{n}^{*}\right)=n C l(\{2\})=\{2\}$. Therefore, $n C l(A) \nsubseteq A_{n}^{*}=n C l\left(A_{n}^{*}\right)$.

Definition 3.5. "([4], Definition 2.6) Let $\left(U, \tau_{R}(X)\right)$ be a nano topological space with an ideal $I$ on $U$. The set operator $n C l^{*}$ is named a nano $*$-closure and is defined as:

$n C l^{*}(A)=A \cup A_{n}^{*}$, for $A \subseteq X^{\prime \prime}$. 
Theorem 3.6. ([4], Theorem 2.\%.) The set operator $n C l^{*}$ satisfies the following conditions :

(i) $A \subseteq n C l^{*}(A)$,

(ii) $n C l^{*}(\phi)=\phi$ and $n C l^{*}(U)=U$,

(iii) If $A \subseteq B$, then $n C l^{*}(A) \subseteq n C l^{*}(B)$,

(iv) $n C l^{*}(A) \cup n C l^{*}(B)=n C l^{*}(A \cup B)$.

(v) $n C l^{*}\left(n C l^{*}(A)\right)=n C l^{*}(A)$.

Proof. It is clear from Definition 3.6 and Theorem 3.4.

\section{Nano Almost I-open Sets}

The fourth section we have interpreted the properties of nano almost $I$-open sets in terms of its approximations.

Definition 4.1. In a nano ideal topological space $\left(U, \tau_{R}(X), I\right), W \subseteq U$ is called nano almost $I$-open if $W \subseteq n C l\left(n I n t\left(A_{n}^{*}\right)\right),(U$ $W$ ) is called nano almost $I$-closed.

When there is no chance of confusion, the collection of all nano almost $I$-open sets of $\left(U, \tau_{R}(X), I\right)$ will be symbolized by $N A I O\left(U, \tau_{R}(X)\right)$. Also, $N A I O(U, x)$ means the class of all nano almost $I$-open sets containing $x \in U$.

" Recall that, a subset $A$ of a nano ideal topological space $\left(U, \tau_{R}(X), I\right)$ is named nano $I$-open [9] if $A \subseteq n \operatorname{Int}\left(A_{n}^{*}\right)$."

Proposition 4.2. Arbitrary union of nano almost I-open sets is also nano almost I-open.

Proof. Let $\left(U, \tau_{R}(X), I\right)$ be any nano ideal topological space and $W_{i} \in N A I O\left(U, \tau_{R}(X)\right)$ for $i \in \nabla$. This means that for each $i \in \nabla, W_{i} \subseteq n C l\left(n \operatorname{Int}\left(W_{i}\right)_{n}^{*}\right)$ and so, $\cup_{i \in \nabla} W_{i} \subseteq \cup_{i \in \nabla} n C l\left(n \operatorname{Int}\left(W_{i}\right)_{n}^{*} \subseteq n C l\left(n \operatorname{Int}\left(\cup_{i \in \nabla} W_{i}\right)_{n}^{*}\right)\right.$. Hence $\cup_{i \in \nabla} W_{i} \in$ $N A I O\left(U, \tau_{R}(X)\right)$.

Remark 4.3. A finite intersection of nano almost $I$-open sets need not in general be nano almost $I$-open as shown in the next example.

Example 4.4. Let $U=\{1,2,3,4\}$ be the universe, $U / R=\{\{2\},\{4\},\{1,3\}\}, X=\{1,4\}$. Then $\tau_{R}(X)=\{U, \phi,\{4\},\{1,3\},\{1,3,4\}\}$. For $I=\{\phi,\{4\}\}$, we deduce that the two sets $A=\{1,2\}$ and $B=\{2,3\}$ are nano almost $I$-open while their intersection $C=\{2\}$ does not nano almost I-open.

The connections between nano almost $I$-openness with some other corresponding types have been given throughout the following implication in Figure 2.

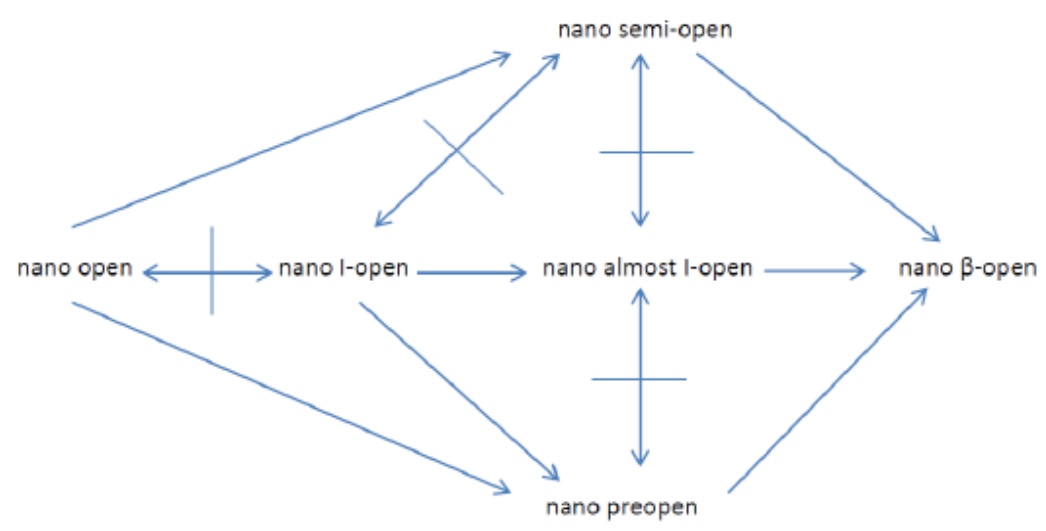

Figure 2: Relationship between some forms of near nano open sets.

The above relationship can not be reversible as the following examples illustrate. 
Example 4.5. Let $U=\{1,2,3,4\}$ be the universe, $U / R=\{\{2\},\{4\},\{1,3\}\}$ be the family of the equivalence classes of $U$ by the equivalence relation $R$ and $X=\{1,4\}$. Then one can deduce that:

$\operatorname{apr}(X)=\{4\}, \overline{\operatorname{apr}}(X)=\{1,3,4\}$ and $B_{R}(X)=\{1,3\}$. Therefore, the nano topology $\tau_{R}(X)=\{U, \phi,\{4\},\{1,3\},\{1,3,4\}\}$. $\overline{F o r} I=\{\phi,\{4\}\}$, we can show the following:

(i) The set $A=\{1,2\}$ is nano almost I-open but is not nano I-open.

(ii) The set $B=\{1,2,4\}$ is nano peopen but not nano I-open.

Example 4.6. Let $U=\{1,2,3,4\}$ with $U / R=\{\{1\},\{3\},\{2,4\}\}$ and $X=\{1,2\}$. Then one can deduce that apr $(X)=$ $\{1\}, \overline{\operatorname{apr}}(X)=\{1,2,4\}$ and $\tau_{R}(X)=\{U, \phi,\{1\},\{2,4\},\{1,2,4\}\}$. If $A=\{2,3\}$, then $A$ is nano $\beta$-open but neither nano preopen nor nano semi-open.

Example 4.7. Let $U=\{1,2,3,4\}$ with $U / R=\{\{3\},\{4\},\{1,2\}\}$ and $X=\{1,3\}$. Then one can deduce that apr $(X)=$ $\{3\}, \overline{\operatorname{apr}}(X)=\{1,2,3\}, B_{R}(X)=\{1,2\}$. Therefore $\tau_{R}(X)=\{U, \phi,\{3\},\{1,2\},\{1,2,3\}\}$. Now $A=\{1,4\}$ is nano $\bar{\beta}$-open in $U$ but not nano almost $I$-open in $U$, where $I=\{\phi,\{1\}\}$.

Proposition 4.8. In a nano ideal topological space $\left(U, \tau_{R}(X), I\right)$, if $G \in \tau_{R}(X)$ and $H \in N A I O\left(U, \tau_{R}(X), I\right)$, then $G \cap H$ is nano almost I-open.

Proof. By assumption and the fact that $G \cap n C l(H) \subseteq n C l(G \cap H)$, we have, $G \cap H \subseteq G \cap n C l\left(n I n t(H)_{n}^{*}\right) \subseteq n C l(G \cap$ $\left.n \operatorname{Int}(H)_{n}^{*}\right)$. Then we have $G \cap H \subseteq n C l\left(n \operatorname{Int}\left(G \cap(H)_{n}^{*}\right)\right) \subseteq n C l\left(n \operatorname{Int}\left((G \cap H)_{n}^{*}\right)\right)$. Hence the result.

Proposition 4.9. The following statements are hold.

(i) For $\left(U, \tau_{R}(X),\{\phi\}\right)$, then $N A I O\left(U, \tau_{R}(X)\right)=N \beta O\left(U, \tau_{R}(X)\right)$.

(ii) For $\left(U, \tau_{R}(X), P(U)\right)$, then $N A I O\left(U, \tau_{R}(X)\right)=N I O\left(U, \tau_{R}(X)\right)$.

(iii) For any nano ideal topological space $\left(U, \tau_{R}(X), I\right)$, each nano almost $I$-open which it is nano $*$-closed is nano semi-open.

(iv) For any nano ideal topological space $\left(U, \tau_{R}(X), I\right)$, each nano semi-open which it is nano $*$-dense in itself is nano almost I-open.

\section{$5 \quad$ Nano Almost I-Continuous Functions}

First we introduce a weak form of nano $I$-continuous function (cf. Definition 5.5) called nano almost $I$-continuous (Definition 5.1 below)

Definition 5.1. A function $f:\left(U, \tau_{R}(X), I\right) \rightarrow\left(V, \tau_{R^{\prime}}(X)\right)$ is named nano almost $I$-continuous (briefly, naI-continuous) if for every $G \in \tau_{R^{\prime}}(X), f^{-1}(G) \in N A I O\left(U, \tau_{R}(X)\right)$.

The next theorem gives several characterizations of nano almost $I$-continuous functions.

Theorem 5.2. For $f:\left(U, \tau_{R}(X), I\right) \rightarrow\left(V, \tau_{R^{\prime}}(X)\right)$ be a function, the next are equivalent:

(i) $f$ is naI-continuous.

(ii) The reverse image of each nano closed set in $\left(V, \tau_{R^{\prime}}(X)\right)$ is a nano almost $I$-closed in $\left(U, \tau_{R}(X), I\right)$.

(iii) For each $x \in U$ and each $G \in \tau_{R^{\prime}}(X)$ including $f(x)$, there exists $W \in N A I O(U)$ containing $x$ such that $f(W) \subseteq G$.

(iv) For each $x \in U$ and each $G \in \tau_{R^{\prime}}(X)$ including $f(x),\left(f^{-1}(G)\right)_{n}^{*}$ is a nano neighbourhood of $x$.

Proof. (i) $\Leftrightarrow($ ii): Obvious

(i) $\Rightarrow$ (iii): Let $x$ in $X$ and $G$ be a nano almost $I$-open set of $Y$ including $f(x)$. By (i), $f^{-1}(G)$ is a nano almost $I$-open set. Set $W=f^{-1}(G)$, we have $f(W) \subseteq G$.

(iii) $\Rightarrow$ (i): Let $A$ be a nano open set in $Y$. If $f^{-1}(A)=\phi$, then $f^{-1}(A)$ is clearly a nano almost $I$-open set. Assume that $f^{-1}(A) \neq \phi$. Let $x \in f^{-1}(A)$. Then $f(x) \in A$, which implies that there exists a nano almost $I$-open set $W$ including $x$ such that $f(W) \subseteq A$. Thus, $W \subseteq f^{-1}(A)$. Since $W$ is nano almost $I$-open, $x \in W \subseteq n \operatorname{Int}\left(W_{n}^{*}\right) \subseteq n \operatorname{Int}\left(f^{-1}(A)_{n}^{*}\right)$ and so $f^{-1}(A) \subseteq n \operatorname{Int}\left(f^{-1}(A)_{n}^{*}\right)$. Hence $f^{-1}(A)$ is nano almost $I$-open set and so $f$ is nano almost $I$-continuous.

(iii) $\Rightarrow$ (iv): Let $x \in X$ and $G$ be a nano open set of $Y$ including $f(x)$. Then there exist a nano almost $I$-open set $W$ including $x$ such that $f(W) \subseteq G$. It follows that $W \subseteq f^{-1}(f(W)) \subseteq f^{-1}(G)$. Since $W$ is nano almost $I$-open, $x \in W \subseteq n I n t\left(W_{n}^{*}\right) \subseteq$ $n \operatorname{Int}\left(f^{-1}(G)_{n}^{*}\right) \subseteq f^{-1}(G)_{n}^{*}$. Hence $f^{-1}(G)_{n}^{*}$ is nano almost $I$-continuous of $x$.

(iv) $\Rightarrow(\mathrm{i})$ : Obvious 
Proposition 5.3. The next equivalents are verify:

(i) $f:\left(U, \tau_{R}(X),\{\phi\}\right) \rightarrow\left(V, \tau_{R^{\prime}}(X)\right)$ is nano almost I-continuous if and only if it is nano $\beta$-continuous.

(ii) $f:\left(U, \tau_{R}(X), P(X)\right) \rightarrow\left(V, \tau_{R^{\prime}}(X)\right)$ is nano almost $I$-continuous if and only if it is nano I-continuous.

(iii) Nano almost I-continuity of a function $f:\left(U, \tau_{R}(X), I\right) \rightarrow\left(V, \tau_{R^{\prime}}(X)\right)$ concides with nano semi-continuity if for each $G \in \tau_{R^{\prime}}(X), f^{-1}(G)$ is nano $*$-perfect or $f^{-1}(G)$ is both nano $*$-dense-in-itself and nano $*$-closed.

Definition 5.4. Let $\left(U, \tau_{R}(X)\right)$ and $\left(V, \tau_{R^{\prime}}(Y)\right)$ be two nano topological spaces. A mapping $f:\left(U, \tau_{R}(X)\right) \rightarrow\left(V, \tau_{R^{\prime}}(Y)\right)$ is called nano $\beta$-irresolute if $f^{-1}(B)$ is nano $\beta$-open in $U$ for every nano $\beta$-open set $B$ in $V$.

Proposition 5.5. For the function $f:\left(U, \tau_{R}(X), I\right) \rightarrow\left(V, \tau_{R^{\prime}}(X), J\right)$ and $g:\left(V, \tau_{R^{\prime}}(X), J\right) \rightarrow\left(W, \tau_{R^{\prime}}(X)\right)$, the following are hold:

(i) If $f$ nano almost $I$-continuous and $g$ is nano continuous, then the composition $(g \circ f)$ is nano almost $I$-continuous.

(ii) $(g \circ f)$ is nano $\beta$-continuous, if $f$ is nano $\beta$-irresolute and $g$ is nano almost $I$-continuous.

Definition 5.6. Let $\left(U, \tau_{R}(X), I\right)$ be a nano ideal topological space and $\left(V, \tau_{R^{\prime}}(Y)\right)$ be a nano topological space. A mapping $f:\left(U, \tau_{R}(X), I\right) \rightarrow\left(V, \tau_{R^{\prime}}(Y)\right)$ is called nano $I$-continuous [7] if the reverse image for every nano open set $B$ in $V$ is nano $I$-open in $U$.

Relationship of several functions defined in this research, from the Figure 3.

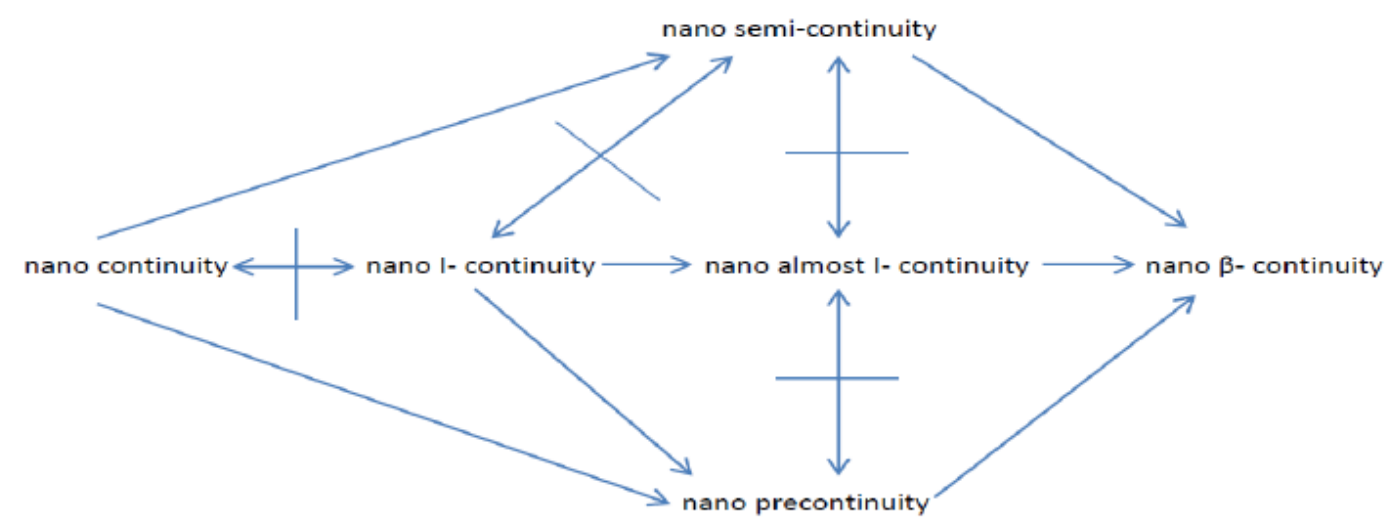

Figure 3: Relationship between some weak forms of nano continuity.

The reverses need not be true in general as shown in the next examples.

Example 5.7. Let $U=\{1,2,3,4\}$ with $U / R=\{\{1\},\{4\},\{2,3\}\}$ and $X=\{1,4\}$. Then one can deduce that $\tau_{R}(X)=$ $\{U, \phi,\{1,4\}\}$. Let $V=\{x, y, z, w\}$ with $V / R^{\prime}=\{\{x\},\{z\},\{y, w\}\}$ and $Y=\{x, y\}$. Then $\tau_{R^{\prime}}(Y)=\{V, \phi,\{x\},\{y, w\},\{x, y, w\}\}$. Define $f:\left(U, \tau_{R}(X)\right) \rightarrow\left(V, \tau_{R^{\prime}}(Y)\right)$ as: $f(1)=y=f(2), f(3)=z, f(4)=w$. It is clear that $f$ is both nano semi-continuous and nano precontinuous but not nano continuous.

Example 5.8. Let $U=\{1,2,3,4\}$ with $U / R=\{\{1\},\{3\},\{2,4\}\}$ and $X=\{1,2\} \subseteq U$. Then one can deduce that $\tau_{R}(X)=$ $\left\{U, \phi,\{1\},\{2,4\},\{1,2,4\}\right.$. Let $V=\{x, y, z, w\}$ with $V / R^{\prime}=\{\{y\},\{w\},\{x, z\}\}$ and $Y=\{x, y\} \subseteq V$. Then $\sigma_{R^{\prime}}(Y)=$ $\{V, \phi,\{x, z\},\{x, y, z\}\}$. Define $f:\left(U, \tau_{R}(X)\right) \rightarrow\left(V, \sigma_{R^{\prime}}(Y)\right)$ as: $f(1)=z, f(2)=x, f(3)=w, f(4)=y$. It is clear that $f$ is nano $\beta$-continuous but not nano semi-continuous.

Example 5.9. Let $U=\{a, b, c, d, e\}$ with $U / R=\{\{b\},\{d\},\{e\},\{a, c\}\}$. Let $X=\{a, b, c\} \subseteq U$. Then one can deduce that $_{R}(X)=\{U, \phi,\{a, b, c\}\}$. Let $V=\{1,2,3,4,5\}$ with $V / R^{\prime}=\{\{1\},\{2,5\},\{3,4\}\}$ and $Y=\{1,2,5\} \subseteq V$. Then $\tau_{R^{\prime}}(Y)=$ $\{V, \phi,\{1,2,5\}\}$. Define $f:\left(U, \tau_{R}(X)\right) \rightarrow\left(V, \tau_{R^{\prime}}(Y)\right)$ as: $f(a)=5, f(b)=1, f(c)=2, f(d)=3, f(c)=4$. It is clear that for $I=\{\phi,\{b\},\{c\},\{b, c\}\}, f$ is nano $\beta$-continuous but not nano almost $I$-continuous. 


\section{Conclusion}

It is shown that we are interested in finding the notion of nano almost $I$-open sets and nano almost- $I$-continuous functions in nano ideal topological spaces and some of their properties are studied. It is to be expected that this paper is just a beginning of a new structure. It will inspire many to contribute to the cultivation of nano ideal topology in the field of mathematics.

\section{Acknowledgement}

The authors are grateful to referees for useful comments and suggestions.

\section{References}

[1] K. Kuratowski, Topologies I, Warszawn, 1933.

[2] R. Vaidyanathaswamy, The localization theory in set-topology, Proc. Indian Acad. Sci., 20(1945), 51-61.

[3] M. L. Thivagar and C. Richard, On nano forms of weakly open sets, International Journal of Mathematics and Statistics Invention, 1(1)(2013), 31-37.

[4] M. Parimala; T. Noiri and S. Jafari, New types of nano topological spaces via nano ideals, 2016 communicated.

[5] Z. Pawlack, Rough sets, International Journal of Information and Computer Scinces, 11(5)(1982), 341-356.

[6] M. L. Thivagar and C. Richard, On nano continuity, Mathematical Theory and Modeling, 7(2013), 32-37.

[7] A. A. Nasef; A. I. Aggour and S.M. Darwesh, On some classes of nearly open sets in nano topological spaces, Journal of the Egyptian Mathematical Society (2016), 1-5.

[8] M. L.Thivagar and V. S.Devi, New sort of operators in nano ideal topology, Ultra Scientist Vol. 28(1)A, (2016), 51-64.

[9] M. Parimala and S. Jafari, Decomposition of continuity in nano ideal topological space, 2017 (Communicated). 